\title{
CROWDFUNDING Y FINANCIACIÓN DE PARTIDOS POLÍTICOS
}

\author{
ADRIÁN PALMA ORTIGOSA
}




\section{SUMARIO}

I. UNA REGULACIÓN INESPERADA. II. ¿QUÉ ES EL CROWDFUNDING? III. MANIFESTACIÓN DEL CROWDFUNDING EN LA FINANCIACIÓN DE LOS PARTIDOS POLÍTICOS. 1. El crowdfunding en las campañas electorales. 2. El crowdfunding en la financiación ordinaria de los partidos políticos. IV. LOS RIESGOS DEL CROWDFUNDING EN LA FINANCIACIÓN DE PARTIDOS POLÍTICOS. V. ENCAJE LEGAL. 1. La viabilidad legal de la financiación participativa en los procesos electorales. 2. El encaje legal del crowdfunding en la LOFPP. 3. Limitaciones a las cuantías aportadas. 4. Instrumentalización de las aportaciones crowdfunding. VI. LA CONSTITUCIONALIDAD DEL CROWDFUNDING. 1. Derechos latentes en las aportaciones crowdfunding. 2. La proporcionalidad de la medida. CONCLUSIONES. 


\title{
CROWDFUNDING Y FINANCIACIÓN DE PARTIDOS POLÍTICOS
}

\author{
ADRIÁN PALMA ORTIGOSA ${ }^{1}$ \\ Universidad de Valencia
}

\section{UNA REGULACIÓN INESPERADA²}

El día 20 de diciembre de 2014, el Tribunal de Cuentas alertaba de las posibles irregularidades en algunas de las aportaciones provenientes vía crowdfunding en favor de la agrupación política Podemos, recomendado para ello una regulación que tratara de adecuarse a estas nuevas formas de captación de fondos por parte de los partidos políticos ${ }^{3}$. Menos de un mes después, el legislador decidió incluir durante la tramitación parlamentaria de la Ley orgánica 3/2015, de 30 de marzo, de control de la actividad económico-financiera de los Partidos Políticos, que reforma la Ley orgánica 8/2007, de 4 de julio, sobre financiación de los partidos políticos (en adelante LOFPP) un precepto que versara sobre la articulación de dicha herramienta. Este precepto fue el art. 4.2 h) de la citada norma. Sin embargo, y como ahora profundizaremos, el reconocimiento legal de la financiación participativa y más concretamente del uso del crowdfunding como nueva forma de soporte financiero de los partidos políticos a través de dicho precepto, ha sido cuanto menos contradictorio y poco acertado. En este estudio, trataremos de justificar y en su caso proponer una reforma de nuestro ordenamiento jurídico que reconozca y regule de forma más coherente esta nueva herramienta de la que puedan hacer uso las agrupaciones políticas.

${ }_{1}$ Contratado Pre Doctoral. Generalitat Valenciana. Departamento de Derecho Constitucional, Ciencia Política y de la Administración.

Facultad de Derecho - Universidad de Valencia). Avda.dels Tarongers, s/n. 46022 Valencia (España). Email: adrian.palma@uv.es

2 Este estudio ha sido realizado con el apoyo del Plan Propio 2017 de la UGR en relación a las Becas de Iniciación a la investigación para estudiantes de másteres oficiales.

A su vez, mi agradecimiento a Miguel Azpitarte por los consejos y observaciones planteadas. Los posibles errores y opiniones contenidas en este trabajo son exclusivamente responsabilidad del autor del mismo.

3 Véase Informe N. 1.065 de fiscalización de las contabilidades de las elecciones al parlamento europeo de 25 de mayo de 2014. En sesión celebrada el 20 de diciembre de 2014, recomendación 3. a, pág. 44. 
Cabe subrayar que este trabajo se presenta en un momento en el que tanto en el Congreso de los Diputados como en el Senado, se está debatiendo la manera de poder introducir esta nueva fuente de ingresos más allá de la deficiente regulación que presenta nuestras normas actuales en materia de financiación de partidos políticos sobre la susodicha herramienta ${ }^{4}$.

\section{II. ¿QUÉ ES EL CROWDFUNDING?}

Para poder analizar y en su caso justificar la viabilidad legal del crowdfunding en las normas que regulan la financiación de los partidos políticos, se hace necesario realizar un primer acercamiento a la naturaleza jurídica de este fenómeno. Advirtiendo con ello al lector de que en los primeros párrafos de este estudio nos alejaremos del análisis propiamente dicho de la financiación de los partidos políticos.

Así, y como premisa, conviene indicar que el crowdfunding se incluye dentro de lo que se ha denominado «economía colaborativa», esta última engloba a un conjunto heterogéneo y cambiante de modos de consumo por el que los agentes comparten de forma innovadora bienes o servicios, en muchos casos infrautilizados, a cambio generalmente de un valor monetario, valiéndose para ello de plataformas sociales digitales que permiten la interacción de dichos agentes ${ }^{5}$. Son por tanto las plataformas electrónicas las que constituyen el elemento clave para el desarrollo del fenómeno de la economía colaborativa, ya que sirve de instrumento eficaz para la búsqueda y colaboración entre los proveedores y los receptores de bienes o servicios ${ }^{6}$.

Concretamente, el crowdfunding es una de esas esferas de la economía colaborativa que más ha incidido en la sociedad de hoy en día derivado de la especial relación que tiene esta herramienta en el desarrollo de nuevos proyectos innovadores, así como en el lanzamiento o en la expansión de PYMES ${ }^{7}$. El origen de este mecanismo surge de la fusión de dos conceptos, por un lado, el crowdsourcing, que vendría a ser la recopilación de contribuciones de muchas personas para lograr una meta. Ejemplo: Wikipedia. Y por otro lado, la llamada micro-financiación ${ }^{8}$, que como su propio nombre

4 Tanto la «Comisión para la auditoría de la calidad democrática, la lucha contra la corrupción y las reformas institucionales y legales» en el Congreso de los Diputados, como la «Comisión de investigación de la financiación de los partidos políticos» en el Senado, se están debatiendo las nuevas fórmulas de obtención de fondos de los partidos políticos, y en concreto, se está haciendo especial hincapié en el crowdfunding.

5 Definición señalada por la CNMC en el Estudio titulado: «Estudio sobre los nuevos modelos de prestación de servicios y la economía colaborativa». Marzo de 2016. Pág11.

6 RODRÍGUEZ MARTÍNEZ, I. (2017). «El servicio de mediación electrónica y las plataformas de economía colaborativa». Revista de Derecho Mercantil, n. ${ }^{\circ}$ 30, págs. 181-216.

7 Se calcula que en 2015 se lograron 4200 millones de euros con plataformas de crowdfunding en la UE. Datos obtenidos de la Comisión Europea: Crowdfunding in the EU Capital Markets Union. 3/5/2016.

${ }^{8}$ BRADFORD, C. Steven. (2012). "Crowdfunding and the federal securities laws». Columbia Business Law Review, pp. 1-150. Desde el punto de vista jurídico, este texto es una referencia para todo aquel que hace una primera aproximación al estudio del fenómeno del crowdfunding. 
indica, supone la aportación de pequeñas cantidades para financiar un determinado proyecto?

Pues bien, señalado lo anterior, es turno de hacer mención a los tres sujetos que están presentes en este fenómeno. Por un lado, podemos encontrar la figura del solicitante de fondos, que sería la persona física o jurídica que recibe la financiación para llevar a cabo el proyecto propuesto. Trasladado a la esfera de la financiación de los partidos políticos, los promotores serían las asociaciones políticas. Seguidamente, destaca la figura del mecenas, que vendría a ser la persona física o jurídica que aporta fondos al proyecto. En nuestro trabajo, se correspondería con el ciudadano que decide destinar parte de sus recursos a financiar un proyecto de un determinado partido político. Por último, y como tercer agente, encontramos a las plataformas de financiación, siendo aquel ente que facilita a través de su página web la canalización directa de las aportaciones entre el solicitante de fondos y el mecenas ${ }^{10}$. Son estas últimas, el elemento novedoso esencial que ha entrado a formar parte de este mercado.

Junto con los agentes, hemos también de señalar los cuatro modelos básicos que hasta la fecha han sido reconocidos por parte de la doctrina en relación al tipo de instrumento que es utilizado para estructurar la captación de fondos a través del crowdfunding ${ }^{11}$. Así, dentro de este concepto genérico, podemos distinguir en primer lugar el crowdfunding donativo. Mediante este modelo, los usuarios realizan aportaciones sin ánimo de lucro a proyectos que normalmente llevan aparejados un claro tinte social. Precisamente, este modelo es el que ha sido utilizado por los partidos políticos para financiar sus campañas electorales y sus gastos ordinarios. En segundo lugar, tocaría hablar del crowdfunding mediante recompensa, en este caso, las aportaciones que se realizan tienen una doble finalidad, por un lado, los aportantes apoyan un determinado proyecto, y, por otro lado, la aportación se materializa a su vez en la entrega

\footnotetext{
9 Junto con el Art 4.2 h) de la Ley de Financiación de Partidos políticos, el crowdfunding también ha encontrado su desarrollo legal en la Ley 5/2015 de 27 de abril, de fomento de la financiación empresarial. Esta ley regula esencialmente la actividad de las Plataformas de financiación participativa, como nuevo intermediario en la captación de fondos donde prima el componente financiero. Entre otros: GALACHO ABOLAFIO, A. F. (2017). «Crowdfunding y shadow banking»: plataformas de financiación participativa (PFPS) y la protección de los inversores.». Revista de Derecho Bancario y Bursátil, n. ${ }^{\circ}$ 145, enero-marzo, págs. 173-203. HERNÁNDEZ SAINZ, E. (2015). «La transparencia como instrumento de protección de los inversores en PYMEs y start-ups a través de plataformas electrónicas de financiación participativa (crowdfunding de inversión)». Revista de Derecho del Mercado de Valores, n. ${ }^{\circ}$ 16, Sección Estudios, Págs. 8 y ss. LÓPEZ ORTEGA, R. (2016). «Las plataformas de Financiación participativa (crowdfunding) en la ley 5/2015, de 27 de abril, de fomento de la financiación empresarial». Revista de Derecho Bancario y bursátil, N. ${ }^{\circ} 144$, Octubre -Diciembre, págs. 83-106, pág. 87

${ }^{10}$ CAMACHO CLAVIJO, S. (2016). «El crowdfunding: régimen jurídico de la financiación participativa en la ley 5/2015 de fomento de la financiación empresarial». Revista CESCO de Derecho de Consumo, N. ${ }^{\circ} 17$, Pág. 89.

${ }^{11}$ Entre otros muchos. RODRÍGUEZ DE LAS HERAS BALLEL, T. (2014). «El crowdfunding como mecanismo alternativo de financiación de proyectos». Revista de Derecho Empresarial San José, Costa Rica, n. ${ }^{\circ}$ 1, Págs. 121-140.
} 
de un premio, que generalmente se corresponde con el valor de la propia contribución. Así, a modo de ejemplo, muchos grupos musicales se han visto beneficiados de esta forma de financiación en la medida que, toda persona que colaborara en el proyecto de una maqueta musical, posteriormente es recompensada con la entrega de dicha maqueta o disco del grupo. En tercer lugar, hemos de hablar del crowdfunding mediante acciones, en esta modalidad, la financiación en masa de proyectos se concretiza a través de la participación de los aportantes en el capital de la sociedad que solicita los fondos. Finalmente, y en cuarto lugar, encontramos el crowdfunding basado en préstamos, donde los usuarios conceden préstamos a los promotores de los proyectos para que estos puedan llevarlos a ejecución, siendo posteriormente devueltos dichos préstamos con o sin intereses.

Es importante recalcar el gran paralelismo que existe entre estos modelos de crowdfunding y las figuras clásicas que estos engloban como la donación, el préstamo, etc., Sin embargo, la diferencia esencial y por tanto la característica que hace al crowdfunding como un fenómeno que merece un distinto tratamiento legal es, la aparición de ese tercer agente que interactúa entre el aportante y el que recibe la aportación, es decir, la plataforma. Junto a ello, ha de señalarse que en toda aportación vía crowdfunding siempre estará presente el carácter finalista, aspecto que no siempre se encontrará latente en dichas figuras clásicas.

Finalmente, por lo que se refiere al funcionamiento del crowdfunding, este es relativamente sencillo, de esta manera, una vez que el promotor lanza o pública su proyecto en la plataforma de financiación, inmediatamente, se señala cual es la cantidad que solicita el promotor, tiempo para conseguir dicho montante, así como un indicador donde establece los fondos que hasta ese momento se han obtenido. Acabada dicha campaña, son dos las situaciones que pueden desprenderse, o bien, dicha campaña obtiene los fondos necesarios y el proyecto se lleva a cabo, o bien, no se alcanzan los fondos suficientes. En la segunda de las situaciones, el destino de las aportaciones variará en función del tipo de campaña por la que haya optado el promotor. Así, hay que distinguir aquellas campañas en las que el proyecto se mantiene independientemente de que no se haya conseguido el montante propuesto en el plazo señalado, de las llamadas campañas All or Nothing, es decir, el proyecto se retira si no se alcanza la cuantía establecida una vez llegado el plazo, debiendo devolverse dichas aportaciones ${ }^{12}$.

En definitiva, de lo dicho anteriormente y trasladado ello a la esfera de los partidos políticos, mediante el crowdfunding, un partido político solicita financiación a un conjunto de personas para llevar a cabo un proyecto, debiendo dichas aportaciones destinarse concretamente a la ejecución del mencionado proyecto.

12 Precisamente, el Art. 69 de la Ley 5/2015, de 27 de abril, de fomento de la financiación empresarial, ha optado por seguir el modelo All or Nothing. Véase también: G.WANG, J y YYANG, J.(2016). Financing without Bank Loans. New Alternatives for Funding SMEs in China, Singapur, Ed. Springer, pág. 152. 


\section{MANIFESTACIÓN DEL CROWDFUNDING EN LA FINANCIACIÓN DE LOS PARTIDOS POLÍTICOS}

Llegados a este punto, toca analizar las manifestaciones concretas de este fenómeno en la financiación de los partidos políticos, esto es, por un lado, aquellos casos en los que los partidos han hecho uso del crowdfunding durante el periodo electoral, y por otro lado, como método para sufragar los gastos ordinarios de dichas asociaciones políticas. En ambos casos, el modelo utilizado ha sido el de la donación/aportación, es decir, ciudadano/simpatizante apoya un determinado proyecto propuesto por un partido político sin intención de obtener una contraprestación a cambio.

\section{El crowdfunding en las campañas electorales}

De estas dos formas, la financiación participativa en campañas electorales ha sido sin lugar a dudas la que más veces ha sido puesta en práctica por parte de las asociaciones políticas a la hora de solicitar fondos por medio de esta novedosa fuente de financiación. Además, esta modalidad, ha sido también la que más repercusión social ha tenido hasta la fecha, de hecho, el crowdfunding ha pasado a ser conocido por gran parte de la sociedad española no por su funcionalidad de origen, esto es, ser una herramienta útil a la hora de apoyar nuevas empresas o proyectos de tintes sociales, sino más bien a raíz del uso que han hecho los partidos políticos de esta novedosa herramienta en sus respectivas campañas electorales. Uso que ha destacado esencialmente en países como Reino Unido o EE.UU.

De este modo, el funcionamiento es relativamente sencillo; en primer lugar, un determinado candidato/partido político fija la cantidad estimada que considera que es necesaria para poder financiar en todo o en parte su campaña electoral, así como el plazo en el que se propone conseguirla. En segundo lugar, generalmente, se indica el tipo de aportación máxima y mínima que puede ser entregada por los contribuyentes (mecenas), así como en su caso una breve explicación de cuáles son los objetivos que se pretenden, objetivos, que suelen relacionarse con actuaciones ligadas a la campaña electoral.

Conforme a esta modalidad se han conseguido obtener significativas sumas de dinero procedentes de pequeñas aportaciones de un gran número de personas ${ }^{13}$. La obtención de estos fondos basada en las micro-donaciones se deriva directamente de la propia naturaleza del crowdfunding, que permite y fomenta la realización de pequeñas aportaciones por parte de los simpatizantes de forma sencilla y con un determi-

13 Por ejemplo, el Partido Verde en Reino Unido obtuvo 236.421 libras para financiar su campaña para las elecciones generales al Reino Unido, cuya cuantía media de donación oscilo el importe de 45 libras por persona. Consultado el 5 de julio de 2017 en: http://www.crowdfunder.co.uk/green-partygeneral-election-fighting-fund/? 
nado objetivo ${ }^{14}$. En este sentido, esta nueva herramienta puede mitigar en parte esa desventaja de la que parten todos aquellos partidos políticos que en virtud de los criterios establecidos a la hora de obtener fuentes de financiación pública, se ven en la tesitura de no poder acceder a dichas fuentes de financiación, favoreciendo así con ello el acceso a la competición electoral de partidos y candidatos con cierto apoyo social cuyo reparto de votos está muy disperso, o de fuerzas políticas emergentes que hasta la fecha no han concurrido a ningún proceso electoral y, por consiguiente, no han tenido acceso a la susodicha financiación pública. Se ayuda además a la consecución del principio de igualdad de oportunidades durante el proceso electoral ${ }^{15}$, ya que se reducen las fuertes barreras de entrada que sufren las mentadas agrupaciones políticas $^{16}$, convirtiéndose así el crowdfunding en una vía ideal para abrirse camino en la lucha por la obtención del cuerpo electoral.

\section{El crowdfunding en la financiación ordinaria de los partidos políticos}

Junto con las campañas electorales, el crowdfunding se ha comenzado a utilizar por parte de los partidos políticos para afrontar su financiación ordinaria. El funcionamiento sería el siguiente, en primer lugar, el partido político lanza distintos proyectos de diferentes temáticas y que responden a objetivos muy concretos relacionados con sus gastos ordinarios. Como ejemplos podemos citar: la financiación de los gastos derivados de las sedes de las agrupaciones políticas, obtención de fondos para fletar autobuses de cara a una manifestación, financiar congresos de los partidos, etc. Pues bien, una vez que dicho partido político publica el proyecto en la plataforma para solicitar fondos, en segundo lugar, el turno siguiente les corresponde a los ciudadanos, siendo estos últimos los encargados de financiar dichos proyectos.

A nuestro entender, este funcionamiento favorece una relación más estrecha entre el partido político y los simpatizantes que lo apoyan. Y es que, si bien, son las agrupaciones políticas las que deciden qué proyecto lanzar en base a sus intereses, son los ciudadanos los que en virtud de sus preferencias deciden qué proyecto financiar. Las funcionalidades de esta operatoria pueden ser excelentes para los partidos políticos,

${ }^{14}$ No siempre las donaciones serán de cuantías bajas, se ha demostrado que en muchas campañas del crowdfunding, los promotores prefieren que los aportantes sean pocos y aporten cantidades muy respetables. SUMNERS, P.C. (2013). «Crowdfunding America’s Small Businesses After the JOBS Act of 2012». Review of banking E financial law, Vol. 32, págs. 38-49.

15 SÁNCHEZ MUÑOZ, O. (2015). «La insuficiente reforma de la financiación de los partidos: la necesidad de un cambio de modelo». Revista Española de Derecho Constitucional, n. ${ }^{\circ} 104$, mayo-agosto, págs. 49-82, pág.79.

${ }^{16}$ En relación a la necesidad de establecer reglas que favorezcan la competición electoral. Véase entre otros: MORLOK, M. (2015). «Dos cuestiones clave en la regulación jurídica de los partidos políticos: financiación y democracia interna». Teoría y Realidad Constitucional, n. ${ }^{\circ}$ 35, págs. 183-201, pág. 187. BOIX PALOP, A. (2014). «Modelos de financiación de partidos políticos y corrupción: de los partidos del sistema a los partidos del ciudadano». En: JAREÑO LEAL, A. (dir.): Corrupción pública: cuestiones de política criminal. Madrid, Ed. Iuste, Págs. 168 y ss. 
ya que, mediante este mecanismo, los partidos políticos pueden conocer de primera mano las preferencias tanto de las bases como en su caso de los ciudadanos que deciden financiar un determinado proyecto. Se consigue así logar un filtrado de las distintas inclinaciones de las bases, debido a que estas últimas apoyaran o no los proyectos propuestos por las agrupaciones políticas en base a sus intereses, pero es que además, como dichos proyectos son lanzados al conjunto de población, el lanzamiento de proyectos vía crowdfunding se convierte también en una herramienta ideal para testar los intereses y necesidades de potenciales votantes ${ }^{17}$.

Por supuesto, en las manos del partido político (solicitante de fondos) está la misión de fomentar o en su caso presentar un proyecto más o menos apetecible o más o menos realista para dichos ciudadanos (mecenas). En este orden de cosas, sería muy recomendable la inclusión de foros participativos donde el proyecto pudiera ser mejorado por la retroalimentación de los propios aportantes ${ }^{18}$, en la medida que estos pueden incluir sus propias ideas sobre el proyecto o incluso sobre otros aspectos ligados al partido político.

\section{LOS RIESGOS DEL CROWDFUNDING EN LA FINACIACIÓN DE PARTIDOS POLÍTICOS}

De lo dicho hasta ahora, queda más que claro que las aportaciones crowdfunding se encuadran dentro de las llamadas fuentes de financiación privada de los partidos políticos ${ }^{19}$. Ello supone de antemano que en líneas generales dichas aportaciones gozaran tanto de los aspectos positivos como de los negativos que le son achacados a todo recurso de esta naturaleza.

Haciendo un sucinto repaso de dichas características, la doctrina es prácticamente unánime al señalar que entre los aspectos positivos que están presentes en todo recurso de procedencia privado destaca el fomento o favorecimiento del contacto entre los partidos políticos y la sociedad ${ }^{20}$, ya que se potencia la participación de los simpati-

17 Sobre la importancia de la participación de los ciudadanos en el contexto de la democracia como cauce para conocer sus intereses y preferencias en: OVERTON, S. (2012). "The Participation Interest», Georgetown Law Journal, Vol. 100:1259, Págs.1259 a 1310. Pág.1274. Disponible en: SSRN: https:// ssrn.com/abstract $=2174442$

${ }^{18} \mathrm{La}$ inclusión de canales de comunicación en las campañas de crowdfunding no se considera un servicio básico de las plataformas que proponen este tipo de proyectos, pero si opcional En: GARCÍAPITA Y LASTRES, J.L. (2016) Plataformas de financiación participativa y financial crowdfunding, Valencia, Ed. Tirant Lo Blanch, pág. 92 y ss.

19 Es archiconocida la distinción que hace la doctrina de los tipos de fuentes de financiación de los partidos políticos en relación a su procedencia, esto es, fuentes públicas y privadas.

20 DEL CASTILLO, P. (1994). «Objetivos para una reforma de la legislación sobre financiación de los partidos políticos», en: La financiación de los partidos políticos. Debate celebrado en el Centro de Estudios Constitucionales y políticos, Colección Cuadernos y Debates, Ed. Centro de Estudios Constitucionales, núm. 47, Madrid, pág. 60. 
zantes en el soporte de dichas agrupaciones políticas y se evita además con ello una dependencia exclusiva de dichas formaciones respecto de las fuentes de financiación públicas $^{21}$. En contra, por lo que se refiere a los aspectos negativos, que es lo que ahora nos interesa a nosotros, estos se han concentrado esencialmente en el recelo que estas aportaciones pueden generar respecto de la independencia de los partidos políticos ${ }^{22}$, en la medida que estos últimos puedan verse influenciados por dichas aportaciones.

De esta manera, junto con esos riesgos que están presentes en toda aportación privada que recibe un partido político, a las aportaciones crowdfunding en concreto se le ha atribuido esencialmente un problema. Así, el Tribunal de Cuentas, al aludir al crowdfunding, alertaba de las dificultades de identificación de los contribuyentes o aportantes que instrumentan su financiación a través esta herramienta ${ }^{23}$. De este modo, cualquier persona con un número de cuenta puede realizar un determinado ingreso a un partido político vía on-line, sin que como tal, el DNI, nombre, o la dirección de correo puedan ser necesariamente verdaderos. En este sentido, es reseñable destacar que este riesgo en nuestra opinión no solo está presente en toda aportación vía crowdfunding como así lo hizo notar el Tribunal de Cuentas, sino que dicho riesgo está también presente en toda donación normal que se instrumente a través de internet, donaciones que a día de hoy se realizan por algunos de los principales partidos políticos de nuestro país ${ }^{24}$.

Es por ello que creamos firmemente que esta nueva fuente de financiación no ha de ser erradicada o prohibida, sino que estamos convencidos de que habrá que diseñar una legislación que, permitiendo este nuevo recurso financiero, logre mitigar en parte los riesgos que les viene aparejados. Conforme a esta idea ya se han pronunciado importantes voces provenientes tanto del mundo académico ${ }^{25}$, como del institucional, así, la Comisión Mixta para las Relaciones con el Tribunal de Cuentas ha instado tanto al gobierno como a diversas asambleas legislativas autonómicas a reformar sus respectivas normas relativas a la financiación de las campañas electorales con el fin de «impulsar» las nuevas herramientas de micro financiación basadas en las $\mathrm{TIC}^{26}$.

21 ALGUACIL GONZÁLEZ-AURIOLES, J. (2000) «El problema público de regular jurídicamente la financiación partidaria». Teoría y Realidad Constitucional, n. ${ }^{\circ}$ 6, 2. ${ }^{\circ}$ semestre, págs. 213-223, pág. 220.

22 GARCÍA VIÑUELA, E y VAZQUEZ VEGA, P. (1996). «La financiación de los partidos políticos: un enfoque de elección pública». Revista de Estudios Políticos (Nueva Época), n. ${ }^{\circ}$ 92, abril-junio, págs. 281-296, pág.288.

${ }^{23}$ Informe n. ${ }^{\circ} 1.065$ de fiscalización de las contabilidades de las elecciones al parlamento europeo de 25 de mayo de 2014. En sesión celebrada el 20 de diciembre de 2014, pág. 44.

24 Por ejemplo, el PSOE hace uso de las donaciones vía internet.

25 En los debates que se están llevando a cabo en el Congreso, autores como Benigno Pendas García u Oscar Sánchez Muñoz apuestan firmemente por la regulación del crowdfunding, eso sí, con las cautelas necesarias.

${ }^{26}$ En concreto, por lo que se refiere a la petición de que el Gobierno adopte medidas que fomente el crowdfunding puede consultarse: BOE núm. 187, de 7 de agosto de 2017, páginas 78257 a 78320 , respecto al resto de asambleas parlamentarias consúltese: BOE» núm. 186, de 5 de agosto de 2017, haciendo mención a las Asambleas de las CCAA de Castilla-La Mancha, Cantabria, Región de Murcia y La Rioja. 
Dicho esto, es más que evidente que este trabajo quedaría incompleto si no propusiéramos alternativas legales que respondan a esa premisa, es decir, regulación del crowdfunding sí, pero teniendo en cuenta sus riesgos. Es por ello que en el siguiente capítulo propongamos algunas.

\section{ENCAJE LEGAL}

Vistas las bondades y en su caso los posibles riesgos que puede acarrear el uso de esta nueva herramienta de financiación por parte de los partidos políticos, toca analizar el encaje legal de este nuevo recurso en nuestra legislación Para ello, examinaremos la actual regulación de las dos principales normas que se encargan de establecer la financiación de los partidos políticos, indicando en su caso distintas propuestas legales que serán necesarias para un correcto encuadre del crowdfunding en dicha normativa.

Sin embargo, antes de comenzar con el encaje legal, es necesario indicar que la mayoría de las propuestas legales que se propondrán responderán a una premisa básica basada en la idea de no tender a una excesiva regulación ${ }^{27}$.

Hecha esta aclaración, y dado que nuestro legislador ha optado por una regulación diferenciada entre la financiación de campañas electorales y la financiación ordinaria ${ }^{28}$, no nos queda otra elección que analizar también por nuestra parte el encaje legal de esta herramienta en ambas normativas de forma separada.

\section{La viabilidad legal de la financiación participativa en los procesos electorales}

La Ley Orgánica de Régimen Electoral General (En adelante LOREG), establece una regulación muy parca cuando analiza las fuentes de financiación privada, concretamente, por lo que se refiere al crowdfunding, esta norma no hace referencia alguna en sus preceptos a dicha fuente de financiación. Ello podría llevarnos a pensar que nos encontramos ante un vacío legal en materia de financiación participativa. Precisamente fue esa la conclusión a la que llegó el Tribunal de Cuentas en relación a esta cuestión ${ }^{29}$, sin embargo, no creemos que tal y como está redactada la norma, exista dicho vacío legal.

${ }^{27}$ Se ha señalado que el Derecho de partidos no debería contener ni demasiadas normas, ni normas muy diferenciadas a fin de que los profanos puedan ponerlo en práctica. En: MORLOK, M. (2015) «Dos cuestiones clave en la regulación jurídica de los partidos políticos...», loc,cit, Pág. 194.

${ }^{28}$ La doctrina ha puesto de relieve la necesidad de unificar las normas en materia de financiación de partidos políticos, por todos: ÁLVAREZ CONDE, E. (2013). El derecho de partidos, Madrid, Ed. Colex, págs. 28 y 29.

29 Así ha sido tildado por el Tribunal de Cuentas en algunos de sus informes la situación actual del crowdfunding. Informes de fiscalización de las contabilidades de las elecciones a las asambleas legislativas de 24 de mayo de 2015: N. ${ }^{\circ} 1133$, pág. 32 (Cantabria), N. ${ }^{\circ} 1.134$, pág. 28 (Castilla-La Mancha), N. ${ }^{\circ} 1.135$, PÁG 30 (Extremadura), N. ${ }^{\circ} 1.137$, pág. 32 (La Rioja), N. ${ }^{\circ} 1.136$, pág.,32 (Región de 
Así, cuando la LOREG hace referencia a los recursos privados que pueden soportar las campañas electorales de los partidos políticos, utiliza el concepto «fondos» ${ }^{30}$. Este concepto agrupa todos y cada uno de los recursos que pueden obtener los partidos políticos a la hora de financiar sus gastos electorales, de manera que, a priori, habría que entender que la obtención de recursos a través del crowdfunding podría encuadrarse perfectamente dentro de ese amplio concepto. No obstante, este artículo habría de ponerse en conexión con el Art 126.1 LOREG que viene a exigir a los aportantes de fondos estar debidamente identificados, procediendo para ello, a la exhibición del DNI o pasaporte al empleado de la entidad depositaria. Lo cierto es, que este último precepto parece estar pensando en aquellas aportaciones que se realizan ante una entidad bancaria, sin embargo, nada impediría que dicho DNI pueda ser exhibido vía on-line, a través eso sí, de una copia del DNI o pasaporte, o en su caso, dicho acceso a la plataforma se realizará a través de certificado electrónico, permitiendo así, una plena identificación del aportante ${ }^{31}$.

Ahora bien, independientemente de que con esta interpretación amplia de la norma lleguemos a la conclusión de que el crowdfunding está permitido en los procesos electorales, la realidad es que se hace recomendable una regulación más precisa que favorezca este tipo de financiación. Es por ello que sería ideal que la norma aclarara las formas adecuadas de identificación de los contribuyentes en caso de que las aportaciones se realicen vía crowdfunding. Ello es posible a través de exigencias que permitan una identificación clara por vía on-line, así como la obligatoriedad de que los aportantes declaren en su caso que no se hayan inmersos en ninguna de las prohibiciones que establece la ley en materia de aportaciones a las campañas electorales ${ }^{32}$.

\section{El encaje legal del crowdfunding en la LOFPP}

Por lo que se refiere al encaje legal del crowdfunding en la LOFPP, y a diferencia de la anterior normativa analizada, la LOFPP si ha regulado tímidamente la financiación participativa para sufragar los gastos ordinarios de los partidos políticos. En este sentido, el Art $4.2 \mathrm{~h}$ ) de la LOFPP viene a indicar que las aportaciones procedentes de financiación participativa deberán cumplir los mismos requisitos que las donaciones normales, esto es, que dichas donaciones no sean anónimas, ni revocables, ni finalistas. Así como en su caso el cumplimiento de los mismos límites máximos de cuantías y prohibiciones para determinados entes.

Murcia). Consultado en: http://www.tcu.es/tribunal-de-cuentas/es/sala-de-prensa/news/APROBADOSLOS-INFORMES-DE-LAS-CONTABILIDADES-DE-LAS-ASAMBLEAS-LEGISLATIVAS-DECOMUNIDADES-AUTONOMAS-SIN-OCEX-PROPIO/

30 Véase entre otros el Art 124.1, Art. 125.1 y 2 y Art 126. LOREG

${ }^{31}$ Como así lo prevé ya el Art 84.3 Ley 5/2015 de Fomento de la Financiación Empresarial para el caso de plataformas de financiación participativa bajo el ámbito de esta ley.

32 El Art 128 establece las prohibiciones de determinadas personas físicas y jurídicas a la hora de financiar partidos políticos. 
A priori, cabe señalar que este artículo es cuanto menos escueto y como posteriormente desarrollaremos, resulta del todo contradictorio. De hecho, y como ya anticipábamos en los inicios de este trabajo, la inclusión de este precepto en la ley obedeció a un informe del Tribunal de Cuentas donde ponía en sobre aviso que la financiación vía crowdfunding utilizada por el partido político Podemos había arrojado problemas ligados a la identificación de los donantes ${ }^{3334}$. La prisa en tratar de solventar ese problema derivó en nuestra opinión en una respuesta legal a este fenómeno muy poco atinada, y es que, tal y como está redactado actualmente el precepto, la financiación participativa ordinaria está a día de hoy vetada de facto para cualquier partido político que desee utilizar este mecanismo de obtención de recursos, esta afirmación apodíctica, es ahora desarrollada en las siguientes líneas.

Es por tanto turno de analizar los requisitos que han de cumplir toda aportación proveniente del crowdfunding conforme al Art $4.2 \mathrm{~h}$ ) de la LOFPP. En este sentido, dicho precepto, al aludir a las aportaciones crowdfunding, o como las denomina el legislador, mecanismo de financiación participativa ${ }^{35}$, exige como requisitos mínimos que estas cumplan las mismas exigencias que se establecen para toda donación normal. Por consiguiente, para que sea legal una aportación crowdfunding, estas habrán de ostentar las notas esenciales que están presentes en toda donación normal, siendo las más importantes las notas de irrevocabilidad, prohibición de anonimato y carácter no finalista. Art 4.2 a) y ss. LOFPP.

Dicho ello, pasamos a estudiar las tres exigencias legales.

Por lo que se refiere a la prohibición de las aportaciones anónimas, la norma exige que todo aquel que contribuya a la financiación mediante crowdfunding ha de quedar debidamente identificado. En este sentido, estas contribuciones deben de cumplir los mismos requisitos que se prevén hoy día para las donaciones normales, sin embargo, y dada la incidencia del factor tecnológico que opera en este tipo de contribuciones, la norma deberá de exigir el establecimiento de instrumentos que aseguren dicha identificación, como puede ser el caso del certificado electrónico.

Relacionado con la prohibición de las aportaciones anónimas, y al igual que ocurre con la figura de las donaciones clásicas, hemos de distinguir entre prohibición de anonimato y publicidad de la donación. De este modo, no creemos que a las aportaciones provenientes de crowdfunding se les deba de exigir un mayor grado de transparencia respecto de las donaciones normales. De hecho, y dado que el crowdfunding tiende a fomentar las pequeñas contribuciones, una legislación que exigiera la plena

33 SÁNCHEZ MUÑOZ, O. (2015). «La insuficiente reforma...», loc. cit., pág. 58 y 59.

${ }^{34}$ Dicho informe es: Informe N. 1.065 de fiscalización de las contabilidades de las elecciones al parlamento europeo de 25 de mayo de 2014. En sesión celebrada el 20 de diciembre de 2014, pág. 44. Consultado en: http://www.tcu.es/tribunal-de-cuentas/es/search/alfresco/index.html?showMore=true

35 Es un concepto más amplio que no solo aglutina al crowdfunding, sino que también puede abarcar los llamados microcréditos. 
transparencia para aportaciones que por ejemplo no superaran los $100 €^{36}$, podría llevar consigo el desincentivo de estas, ya que los aportantes prefieren en muchos casos que se desconozca a qué partido político destinan su dinero ${ }^{37}$, y más teniendo en cuenta la cuantía media de las aportaciones crowdfunding. Es por ello que entendamos que los riesgos que acarrea el crowdfunding no justifiquen una diferencia de trato en cuanto a la publicidad de las aportaciones entre las donaciones normales y las provenientes mediante la financiación participativa ${ }^{38}$.

Toca ahora analizar en segundo lugar el carácter irrevocable de las donaciones. De esta manera, cuando un partido político decide lanzar un proyecto o campaña, establece una cuantía mínima que considera adecuada para que se pueda llevar a cabo dicho proyecto. No obstante, es muy frecuente que no todas las campañas o proyectos puedan ser sufragadas suficientemente ${ }^{39}$, lo que automáticamente nos lleva a la cuestión de preguntarnos cuál debería de ser el destino de esas aportaciones una vez que esa campaña no ha tenido éxito. Dicho lo cual, ante esta tesitura, normalmente se tiende a dos soluciones cuando de proyectos de crowdfunding se trata; o bien, el dinero proveniente de las aportaciones se devuelve, o bien, las contribuciones para el proyecto se utilizan porque aunque no sean lo suficientes para llevar a cabo todas las actuaciones, son bastantes para lograr determinados objetivos.

Ahora bien, el funcionamiento descrito es plenamente viable cuando de proyectos de crowdfunding genéricos se trata, pero claro, si trasladamos esa operatoria a la financiación de partidos políticos y a la prohibición de la revocabilidad de las aportaciones de crowdfunding, los problemas aumentan. La pregunta que nos haríamos sería la siguiente, ¿Qué hacemos con esas aportaciones realizadas a través del crowdfunding si la norma prohíbe la revocabilidad y el proyecto no ha conseguido los fondos suficientes?

Para salvar el escollo de la irrevocabilidad, proponemos dos posibles soluciones; o bien, en el momento que el aportante vaya a realizar la aportación, se le indique claramente que dicha aportación en caso de que no se cumpla con el objetivo del proyecto, dicha contribución irá a parar a las arcas comunes del partido político. $O$

36 Esta cuantía ha sido escogida al azar, en este sentido, normalmente, la aportación media vía crowdfunding suele ser inferior.

37 NAVARRO RODRÍGUEZ, tesorera del Partido Popular apuesta por la no publicación de la identidad de los donantes de forma pública. Esta idea fue señalada durante los debates que se están llevando en la Comisión para la auditoría de la calidad democrática, la lucha contra la corrupción y las reformas institucionales y legales. En: Diario de sesiones del Congreso de los Diputados, XII Legislatura, Sesión núm. 165, de 22/03/2017, pág. 11. En cambio, MONTILLA MARTOS, J.A, en la misma comisión, apuesta por la plena transparencia de toda donación privada. En: Diario de sesiones del Congreso de los Diputados, XII Legislatura, Sesión núm. 149, de 08/03/2017. pág.21

38 PENDÁS GARCÍA apuesta por la absoluta transparencia de las donaciones vía crowdfunding, idea aportada en la misma comisión antes citada. En: Diario de sesiones del Congreso de los Diputados XII Legislatura, Sesión núm. 121 de 15/02/2017, pág. 12.

39 «MOLLICK, E. (2014). «The dynamics of crowdfunding: An exploratory study». Journal of Business Venturing, n. ${ }^{\circ}$ 29, págs.1-16. 
bien, podría articularse con la plataforma de crowdfunding un sistema en el cual, los fondos no estén efectivamente transmitidos al partido político hasta que no se cumplen todas las condiciones necesarias. En consecuencia, de no alcanzarse el objetivo establecido, se procedería a la devolución de la aportación por parte de la plataforma, de manera que no habría una revocación en sentido estricto sino más bien una no transmisión de la cantidad recaudada a favor de la agrupación política ${ }^{40}$.

La primera de las soluciones propuesta, si bien puede ser para los partidos políticos la más práctica, también creemos que puede desvirtuar en parte la propia esencia del crowdfunding en la medida que el aportante pueda sentirse defraudado al ver que su aportación finalmente no va destinada a ese proyecto que había decidido financiar, sino que pasa a engrosar los fondos comunes del partido. Junto a este importante inconveniente, esta práctica también puede llevar a los partidos a utilizar el crowdfunding como herramienta para captar fondos que, teóricamente irían destinados a realizar un proyecto, pero en la práctica tendrían como objetivo financiar la actividad común de los partidos políticos. De ahí que, si los partidos políticos hacen uso de esta práctica, deberán de indicar claramente la posibilidad de que esa aportación finalmente vaya a parar a las arcas comunes por imposibilidad de ejecutar el proyecto por falta de fondos. En este sentido, creemos que un aumento de los plazos para la obtención de fondos es una buena solución para intentar materializa el proyecto y evitar con ello que dichos fondos vayan a parar a las arcas comunes.

Por último, en tercer lugar, y no por ello menos importante, se encuentra la exigencia de las aportaciones no finalistas, es sin duda el aspecto que hasta la fecha más controversias está generando en la práctica ${ }^{41}$. Así, cuando en un principio señalábamos que el actual artículo $4.2 \mathrm{~h}$ ) LOFPP resultaba un tanto contradictorio, dicha conclusión devenía de la propia redacción del mencionado precepto al no permitir las aportaciones finalistas cuando se trataba del crowdfunding. En este orden de cosas, hay que tener en cuenta que cualquier aportación que venga de la mano del crowdfunding, exige siempre la existencia de una finalidad, es decir, el destino de esas aportaciones debe de destinarse al cumplimiento de una campaña o proyecto determinado, de ahí que el precepto carezca de sentido.

En nuestra opinión, esta contradicción de la norma deviene de raíz, y ello se debe a que la actual regulación iguala las figuras de las aportaciones provenientes del crowdfunding y la de las donaciones normales. Y es que, cuando el legislador prohíbe las donaciones normales finalistas, trata de evitar dos actuaciones, en primer lugar, que dichas donaciones no vayan destinadas a un gasto en concreto, y en segundo lugar y más importante, evitar que en esas donaciones exista un interés encubierto en el que

40 Este procedimiento es el que se prevé en el Art 69.4 Ley 5/2015 de Fomento de la Financiación Empresarial para aquellos proyectos en los que se estructure bajo los modelos crowdfunding de acciones o préstamos y no consigan la suficiente financiación marcada en un principio.

41 El Partido Popular acuso a Podemos de obtener donaciones finalistas a través del crowdfunding, algo que está actualmente prohibido por la ley. Consultado el 13 de julio de 2017 en: http://www. elmundo.es/espana/2017/07/13/59673207e5fdea4d358b458e.html 
se busca una contraprestación por parte de aquel que la realiza ${ }^{42}$. Sin embargo, el legislador, no se ha percatado del hecho de que toda aportación crowdfunding requiere de ese carácter finalista en el sentido de que toda aportación ha de ir a parar a un proyecto (gasto) concreto. En nuestra opinión, el legislador, al prohibir las aportaciones finalistas procedentes del crowdfunding ha usado la brocha gorda, ya que no ha sabido distinguir, o mejor dicho, no ha querido diferenciar entre aportaciones finalistas que han de estar presentes en el crowdfunding, y figuras delictivas como el cohecho que pueden producirse cuando se realiza una donación normal que busca intereses particulares (finalistas). Resultando por ello del todo ilógico que fuentes de financiación privadas de naturaleza distinta, se le exija a día de hoy los mismos requisitos, y es que, en el momento que el legislador iguala ambas figuras, o más bien, asimila las aportaciones crowdfunding a los requisitos de las donaciones normales, anula el posible uso de dichas contribuciones participativas. Es precisamente el carácter finalista o concretización de la aportación, lo que hace diferente a las contribuciones de crowdfunding de las donaciones normales a partidos políticos.

Esto nos lleva a considerar que este precepto es del todo desatinado en la medida que si bien, podría pensarse que legaliza la financiación participativa, lo cierto es que la hace materialmente inviable, fruto posiblemente de una redacción donde se ha mezclado la prisa por regular este fenómeno, junto con una cierta dosis de falta de conocimiento profundo del funcionamiento del crowdfunding ${ }^{43}$.

Es necesario por tanto que el legislador excepcione el carácter finalista de aquellas aportaciones provenientes del crowdfunding, esto es, que dichas aportaciones puedan ir destinadas a un proyecto o gasto en concreto. En este orden de cosas, la necesidad de exceptuar el carácter finalista de las aportaciones provenientes del crowdfunding fue puesta de manifiesto durante la tramitación de la última reforma de la LOFPP, sin embargo, dicha propuesta no prosperó ${ }^{44}$. Lo cierto es, que dicha enmienda iba por el buen camino de la regulación, así, para que el crowdfunding tenga viabilidad jurídica en la financiación ordinaria de partidos, esto es, bajo el paraguas legal de la LOFPP, es requisito indispensable que las contribuciones que se instrumentalicen a través del crowdfunding se excepcione el requisito de la finalidad, ya que si no, estas aportaciones

42 JIMÉNEZ SÁNCHEZ, F.(2007) «Escándalos de corrupción y defectos de la financiación de los partidos políticos en España: Situación actual y propuestas». Studia politicae, n. ${ }^{\circ} 12$, págs. 67-90, págs. 72 y 73 .

43 No es la primera legislación que denota ese déficit de entendimiento del fenómeno, por ejemplo, la norma portuguesa que regula el crowdfunding financiero permite que la inversión la lleve a cabo un solo inversor respecto de un proyecto, lo que choca con el fundamento básico que reside en el crowdfunding, estos e, la financiación en masa y no la individual, en VIEIRA DOS SANTOS, J. (2017). «Portuguese Crowdfunding Act.». Revista de Derecho Bancario y Bursátil, n. ${ }^{\circ}$ 147, págs. 227-252.

${ }^{4} \mathrm{La}$ enmienda de CIU en el Senado decía: La recepción de donaciones finalistas a través de mecanismos de financiación participativa orientados a la realización de actividades propias de la entidad donataria no vulnera lo establecido en el primer párrafo de este apartado a). Enmienda n. 116 presentada por El Grupo político CIU, durante la tramitación de la última reforma de la LOFPP. BOCG (Senado) de 24 de febrero de 2015, pág. 273. 
no podrán ser nunca legales. En nuestra opinión, la necesidad de esta reforma es acuciante, de hecho, a fecha de hoy, el partido político Podemos está haciendo uso de estas aportaciones ${ }^{45}$. Por consiguiente, hay que entender que se está financiando ilegalmente, lo que se traduce en situaciones en las cuales una aportación de $10 €$ que actualmente esté realizando un simpatizante para financiar un determinado proyecto $^{46}$, puede llevar consigo acarreada no solo una sanción administrativa ${ }^{47}$, sino que, dada la redacción actual del código penal, dicha conducta puede ser constitutiva de delito $^{48}$. Esto último no está del todo claro ya que el nuevo precepto que castiga penalmente las donaciones privadas se centra únicamente en dicha figura, de ahí que si consideramos que el crowdfunding es un recurso privado distinto a las donaciones privadas, como aquí lo defendemos, dicho delito no afectaría a la financiación participativa en general, ni al crowdfunding en particular ${ }^{49}$.

\section{Limitaciones a las cuantías aportadas}

Por lo que se refiere a los límites máximos que una persona puede aportar anualmente a través de una aportación crowdfunding, lo cierto es, que creemos que dichas cuantías máximas han de asemejarse a las que a día de hoy vienen establecidas para las donaciones normales, esto es, $50.000 €$ para gastos ordinarios y $10.000 €$ para gastos electorales, sin perjuicio de que apostemos por una reducción de estos límites para ambas figuras $^{50}$, esto es, tanto para las donaciones como para las aportaciones crowdfunding, esta últimas, caracterizadas por unas aportaciones cuyas cuantías medias son mucho más bajas.

\section{Instrumentalización de las aportaciones crowdfunding}

Por último, habría que preguntarse la forma por la cual se canalizan todas estas aportaciones. En este sentido, los partidos políticos han utilizado dos vías o formas para llevar a la practica el crowdfunding; o bien, son las propias agrupaciones políticas

45 Podemos recibió 271.762,13 y 421.188,63 euros en los años 2014 y 2015 respectivamente procedentes del crowdfunding. Según el Informe N. ${ }^{\circ} 1262$ del Tribunal de Cuentas de 21/12/2017. Además, en los años subsiguientes también ha seguido financiándose a través de esta modalidad de acuerdo a lo establecido en su portal de transparencia alojado en la web de dicha agrupación política.

46 A día de hoy, la agrupación política morada cuanta con media docena de proyectos en los que se solicita financiación ordinaria por medio del crowdfunding.

47 Véanse: Art 17.3 a) y Art 17 bis. 1 a) LOFPP

48 Art 304.bis 1 (para el partido político) y 304 bis 4 (para el que realiza la donación)

49 SAINZ CANTERO CAPARRÓS, J, E. (2015). «Los delitos de financiación ilegal de partidos políticos». En MORILLAS CUEVAS, L (dir): Estudios sobre el Código Penal reformado (Leyes Orgánicas 1/2015 y 2/2015), Madrid, Ed. Dykinson, Pág. 669 in fine y 670 ab initio.

50 En la línea de lo que señala SANCHEZ MUÑOZ, O. (2015). «La insuficiente reforma de la financiación de los partidos...», loc, cit, págs. 76 y 77. 
las que en sus mismas páginas web o afines a estas han desarrollado la estructura de la plataforma y publicado sus respectivos proyectos, es esencialmente la forma que han utilizado hasta la fecha los partidos políticos españoles ${ }^{51}$, o bien, los partidos políticos y candidatos alojan sus distintas campañas y proyectos en plataformas especializadas de crowdfunding.

Ciertamente creemos, que solo en la segunda de las opciones señaladas está presente la auténtica esencia del crowdfunding. Es decir, si dejamos que los partidos políticos puedan diseñar sus propias plataformas o estructuras para canalizar la financiación, el tercer agente que actúa como intermediario externo, esto es, la plataforma de crowdfunding, desaparece. De manera que, se eliminaría en parte uno de los tres agentes que operan en esta nueva forma de canalización y estaríamos simplemente ante el supuesto clásico de una donación, con un mayor o menor elemento electrónico en la transacción.

Además, el segundo modelo señalado potencia la financiación participativa de campañas electorales en la medida en que en dichas plataformas no solo va a aparecer ese candidato o partido político, sino que, junto a él, aparecerán normalmente otra serie de rivales políticos, facilitando con ello que el aportante pueda comparar y finalmente decidir qué partido político apoyar en base a los proyectos propuestos. Este segundo tipo ha tenido especial desarrollo en países donde el fenómeno del crowdfunding está fuertemente implantado como en Reino Unido ${ }^{52}$, o países como EE.UU. donde la financiación política no se centra en el partido político sino en la figura concreta del candidato $^{53}$, por esa idea consustancial de la concepción de la democracia basada en el individualismo. De hecho, en dicho país existen plataformas de crowdfunding especializadas única y exclusivamente en la financiación participativa de candidatos ${ }^{54}$.

Ahora bien, dicho lo anterior, con ello no queremos negar el hecho de que los partidos políticos puedan en su caso crear sus propias plataformas donde el promotor y la plataforma sean el mismo sujeto, simplemente estamos diciendo que ese funcionamiento se aleja del concepto de crowdfunding desarrollado y conocido por la doctrina ${ }^{55}$. En

51 En España, tanto la agrupación política Podemos, como en su caso una fundación afín a Pedro Sánchez durante el proceso de primarias, hicieron uso de esta forma de canalizar los recursos provenientes del crowdfunding.

52 WARDROP, R., ZHANG, B., RAGHAVEBDRA, R. y GRAY, M. (2015). The European Alternative Finance Benchmarking report. Ed. University of Cambridge, February, Págs. 36 a 39. Visto en: https://www.jbs.cam.ac.uk/index.php?id=6481\#.WZ4C31GQzIU

53 Hay que distinguir entre modelos que se centran en financiar al partido político o modelos que se centran en la financiación de los candidatos. En: DEL CASTILLO, P.(1985). La financiación de partidos y candidatos en las democracias occidentales, Madrid, Ed. Siglo XXI de España, pág. 67.

54 En estas plataformas se pueden consultar multitud de candidatos a las distintas elecciones, donde figura diversa información acerca de su proyecto, tipo de aportación que recibe, etc. Consultado en: https://www.crowdpac.com/

55 Algún sector de la doctrina considera viable que la figura del promotor y la plataforma aparezca en determinadas ocasiones representada por la misma figura. En: MORENO SERRANO, E. (2016). «Hacia un crowdfunding de doble vía» en. Hacia un sistema financiero de nuevo cuño: reformas pendientes $y$ andantes. ALONSO LEDESMA, C. (Dir.), Valencia, Tirant lo Blanch, Pág.889. 
manos del legislador está el ser más o menos permisivo, así como en la de los partidos políticos, el optar por incluir sus proyectos en plataformas de crowdfunding ampliamente consolidadas o desarrollar su propia plataforma.

\section{LA CONSTITUCIONALIDAD DEL CROWDFUNDING}

Una vez hemos afirmado en párrafos anteriores que actualmente el crowdfunding está prohibido de facto por la LOFPP, se hace necesario analizar si esta legislación, al prohibir la financiación participativa puede llegar a ser contraria a nuestra Constitución.

Lo cierto es, que para llegar a una solución sólida, nuestra norma suprema no nos lo pone fácil, así, a diferencia de otras constituciones donde la financiación de los partidos políticos aparece mencionada en dichas normas ${ }^{56}$, el constituyente consideró de forma expresa que la financiación de los partidos políticos era una materia que debía de regularse por ley y que por tanto no tenía encaje en la norma suprema ${ }^{57}$, y ello pese a los intentos de algún grupo político de incluirla durante la tramitación de dicha norma ${ }^{58}$. A ello tenemos que añadirle la escasez de pronunciamientos de nuestro máximo intérprete de la Constitución sobre esta temática, pronunciamientos que además se han centrado únicamente en la financiación pública ${ }^{59}$.

Es por todo esto, que haya que partir de la idea inicial de señalar que nuestra Constitución Española no impone de origen ningún modelo de financiación. Sin embargo, ello no puede arrojarnos a la conclusión por la cual cualquier modelo de financiación pudiera resultar admisible ${ }^{60}$, o cualquier fuente de financiación pudiera permitirse.

De esta manera, para poder analizar si la medida legal analizada es contraria a la Constitución, esto es, prohibición de facto absoluta de las aportaciones crowdfunding, nos valdremos del principio de proporcionalidad como parámetro o indicador. En este sentido, creemos que el uso de este test es ideal ya que, lo que vamos a valorar esencialmente en las siguientes líneas no es si las aportaciones crowdfunding han de ser sometidas a unas limitaciones o condicionantes concretos, como así ya lo entendemos, sino que lo que se va a estudiar es si, una prohibición

56 Por ejemplo, Constituciones más antiguas como la alemana. Art 21.1 o algunas más recientes como la del Perú. Art 35.

57 Véase el Informe de la Ponencia designada para estudiar las enmiendas al Anteproyecto de Constitución (publicado en el «B. O. C.» de 17 de abril de 1978), pág. 507. Consultado en: http://www. congreso.es/est_consti/

58 Enmienda núm. 457, presentada por el Grupo Mixto al (Anteproyecto de 5 de enero de 1978), que proponía la financiación de los partidos políticos a cargo de los Presupuestos Generales del Estado. Consultado en: http://www.congreso.es/est_consti/

59 STC Núm. 3/1981 de 2 febrero. FJ 2.

${ }^{60}$ Pueden verse distintas publicaciones del mismo autor. SÁNCHEZ MUÑOZ, O. (2016). «El control de la financiación de los partidos políticos». En: MATILLA PORTILLA, F.J.: Problemas actuales sobre el control de los partidos políticos, Valencia, Ed. Tirant lo Blanch, Pág. 379 
que anula por completo este tipo de aportaciones privadas a los partidos políticos es proporcional al fin que se persigue con dicha medida. Ello nos llevará por tanto en primer lugar, a señalar aquellos posibles derechos fundamentales y principios que están presentes en toda aportación crowdfunding, para después y en segundo lugar, estudiar la proporcionalidad de la medida (Art $4.2 \mathrm{~h}$ LOFPP) por la que se restringen o en su caso se vulneran dichos derechos fundamentales y principios por exceder del test de proporcionalidad.

En este sentido, somos conscientes de los problemas que pueden llevar aparejados el hecho de tildar una determinada ley como inconstitucional por las pocas referencias que existen dentro de nuestra norma suprema a la institución que analizamos, sin embargo, también creemos, que existen razones para considerar que esta fuente de financiación es acorde con la Constitución y por tanto su prohibición contraria a dicha norma suprema.

\section{Derechos latentes en las aportaciones crowdfunding}

Señalado lo anterior, hay que partir de que los partidos políticos, como asociaciones privadas, son titulares del derecho de asociación del Art $22 \mathrm{CE}$, ello implica entre otros aspectos que tienen derecho a recibir fondos procedentes tanto de fuentes públicas como privadas ${ }^{61}$, todo ello, para así poder hacer frente a los gastos cotidianos que se derivan de un funcionamiento permanente ${ }^{62}$, garantizando así la propia estabilidad del sistema democrático ${ }^{63}$.

Ahora bien, no toda fuente de financiación puede valer, sino que dada la relevancia constitucional que ostentan los partidos políticos, solo se permitirán aquellas fuentes que estén presentes en algunos de los principios básicos que conforman el marco jurídico de dichas asociaciones, esto es, el pluralismo propio de todo sistema democrático, la igualdad de oportunidades, el funcionamiento democrático interno, su contribución a la formación y transmisión de la voluntad popular, la libertad frente al Estado y su conexión con la sociedad ${ }^{64}$. En el caso del crowdfunding, lo cierto es, que se trata de una fuente de financiación donde están presentes de forma muy incisiva algunos de los principios que previamente hemos señalado, además y esto también es importante, creemos ciertamente que a través de esta herramienta pueden beneficiarse partidos de distin-

${ }^{61}$ SÁNCHEZ MUÑOZ, O. (2016). «El control de la financiación... loc. cit., pág. 379. También puede verse en el mismo sentido: Art 1. Recomendación Rec (2003) 4 del Comité de Ministros del Consejo de Europa a los Estados miembros relativa a las reglas comunes contra la corrupción en el financiamiento de los partidos políticos y campañas electorales (Adoptada por el Comité de Ministros el 8 de abril del 2003, durante la 835 reunión)

62 Informe adoptado por la Comisión de Venecia titulado: «Guidelines and report on the financing of political parties». Pág. 9. Con fecha del 9 al 10 de marzo de 2001.

63 Véase la exposición de motivos de la LOFPP.

64 NÚÑEZ PÉREZ, M. (2009). «La financiación de los partidos políticos», Revista Española de Control Externo, vol. 11, n. ${ }^{\circ} 33$, págs. 163-174, pág. 165. Véase también: PRESNO LINERA, M.A. (2000). Los partidos políticos en el Sistema Constitucional Español. Ed. Aranzadi. Navarra. Págs. 78 y ss. 
ta índole en los términos explicados en este trabajo, de hecho, en las manos de las agrupaciones políticas residirá el otorgar una mayor importancia o no a este recurso.

Por otro lado, junto con el derecho de asociación, los aportantes, al realizar una determinada aportación privada, también ejercen a su vez una serie de derechos fundamentales. Exactamente, dichos derechos son los de libertad ideológica (Art 16 CE) y libertad de expresión (Art $20 \mathrm{CE})^{65}$. De este modo, el ejercicio de estos derechos se ampara en el fundamento básico por el cual, cualquier ciudadano que realiza una aportación privada, tiene la facultad de apoyar libremente a un partido político de su elección afín a sus ideas a través de una contribución económica ${ }^{66}$. En el crowdfunding, aparte de estar presente dicha facultad general, propia de toda aportación privada, encontramos a su vez un aspecto diferenciador y que en nuestra opinión es esencial. De esta forma, cuando un aportante realiza una contribución a un determinado proyecto, no solo está apoyando a un partido político afín a sus ideas (donación normal), sino que además, está explicitando adónde quiere destinar justamente dicha aportación (aportación finalista), es decir, los derechos de libertad de expresión y libertad ideológica aparecen en estos casos aún más concretizados en la medida que el aportante incide en el destino de la contribución, expresando por tanto, el tipo de participación concreta que desea apoyar. Ello permite que el aportante vía crowdfunding no siempre sea un simpatizante con un perfil que ostente unos compromisos hacia el partido político fuertes y estables ${ }^{67}$, sino que podemos encontrarnos con ciudadanos que sin considerarse de un partido político concreto, deciden apoyar en un momento determinado un proyecto por considerar que es interesante. Pudiendo surgir así la noción de contribuyente o aportante puntual. Esto último facilita que cualquier ciudadano pueda definir libremente la forma con la que se relaciona personalmente con un partido político ${ }^{68}$, contribuyendo así a la financiación de sus ideas, apuestas y decisiones ${ }^{69}$. En este sentido, las campañas vía crowdfunding pueden ser muy prácticas para sufragar eventos concretos como organización de conferencias, foros cívicos, marchas protesta, etc. Así, piénsese por ejemplo en el siguiente supuesto. Un partido $\mathrm{X}$ solicita financiación a través de un proyecto crowdfunding para fletar unos autobuses con el objetivo de dirigirse a una manifestación en la que se defienden los derechos o

65 Sin lugar a dudas, ha sido la doctrina y jurisprudencia norteamericana la que ha relacionado estrechamente el derecho de libertad de expresión con las aportaciones privadas a los partidos políticos. Por todas. Caso Buckley v. Valeo, de 1976 de la Corte Suprema de los EEUU

66 Véase Informe de la Comisión de Venecia, titulado «Guidelines on Political Party Regulation» observación n. ${ }^{\circ} 170$, pág. 69 y 70, adoptado los días 15 y 16 octubre de 2010.

${ }^{67}$ SÁNCHEZ MUÑOZ, O. (2015). «La insuficiente reforma de la financiación de los partidos...», loc,cit, pág.79.

${ }^{68}$ Véase Estudio N. ${ }^{\circ}$ 414/2006 de la Comisión de Venecia, titulado «Código de buenas prácticas en el ámbito de los partidos políticos» concretamente, observación n. ${ }^{\circ} 24$, pág. 9, con fecha de 3 de junio de 2009.

${ }^{69}$ Característica indicada por ESTHER ARIZMEDI GUTIÉRREZ durante la Comisión para la auditoría de la calidad democrática.... En: Diario de sesiones del Congreso de los Diputados, XII Legislatura, Sesión núm. 253, de 07/06/2017, pág. 30. 
intereses de una determinada persona que incluso puede pertenecer a otro partido político, pero que en ese momento puntual, considera que le interesas apoyar financieramente a otra agrupación para ese proyecto en concreto.

Junto con el ejercicio de estos derechos que están presentes en la financiación participativa, consideramos que el crowdfunding se justifica por la existencia de otra serie de factores o principios propios de la financiación de partidos políticos, así, por un lado, mediante esta fuente de financiación, se consiguen alcanzar y potenciar los fines positivos que están presentes en toda aportación privada, esto es, la participación de todos los ciudadanos en la vida política (Art 9.2 CE), contribuyendo así a un mayor acercamiento entre la sociedad y los partidos políticos ${ }^{70}$.

Además, por otro lado, la financiación participativa logra reducir los riesgos que siempre le son achacados a todo recurso de procedencia privada. De esta manera, los ordenamientos jurídicos, al regular las aportaciones privadas desean que, cuando un partido político recibe fuentes de financiación privada, las obtenga de la forma que arroje menos dudas en cuanto a la posibilidad de que en esas contribuciones exista intereses particulares, intereses, que en su caso coarten la manifestación de la voluntad popular y tiendan a reducir la participación política. Sin embargo, la propia naturaleza del crowdfunding, suele llevar consigo aparejada la obtención de pequeñas cantidades aportadas por un gran número de personas, en estos casos, como decíamos, la manifestación de la voluntad popular se hace más presente y el acercamiento entre partido político y sociedad se hace más incisivo. (Art $6 \mathrm{CE}$ ). Acercamiento que como ya previamente señalábamos favorecía a su vez al principio de igualdad de oportunidades, principio que es esencial durante el proceso electoral y que está claramente difuminado actualmente dados los criterios que se establecen para otorgar la financiación pública.

\section{La proporcionalidad de la medida}

Pues bien, una vez formulados los derechos fundamentales y en su caso los principios constitucionales que están presentes en toda aportación vía crowdfunding, es turno de analizar la proporcionalidad de la medida legislativa por la cual, a día de hoy, las aportaciones vía crowdfunding están prohibidas. Para ello, en primer lugar, indicaremos el fin de relevancia constitucional en el que se apoya el legislador para establecer la limitación de estos derechos fundamentales y principios, pasando posteriormente a analizar si dicha medida es o no proporcional al fin perseguido. Por consiguiente, ello nos llevará a analizar la adecuación, la necesidad y la proporcionalidad en sentido estricto de dicha medida legal ${ }^{71}$, y por tanto, a comprobar si nos

70 OLAIZOLA NOGALES, I. (2014) La financiación ilegal de los partidos políticos: un foco de corrupción. Valencia, Ed. Tirant lo Blanch, pág. 104.

${ }^{71}$ GONZÁLEZ BEILFUSS, M. (2006). «Últimas tendencias en la interpretación del principio de proporcionalidad por parte del Tribunal Constitucional». En: PÉREZ ROYO, J.: Derecho constitucional para el siglo XXI: actas del VIII Congreso Iberoamericano de Derecho constitucional, Pamplona, Ed. Aranzadi, págs. 4035-4053. 
hallamos ante una restricción más de estos derechos fundamentales o en cambio ante una auténtica vulneración ${ }^{72}$.

Como premisa previa, y como ya explicábamos en otras líneas, en nuestra opinión, no existe como tal una intención clara de prohibición por parte del legislador de esta fuente de financiación, sino que más bien, y derivado del desconocimiento de esta nueva herramienta, se ha establecido una legislación que hace imposible la puesta en práctica de este recurso. Ello no es óbice para que no creamos necesario hacer este análisis de proporcionalidad, con el objetivo de despejar toda duda de constitucionalidad de esta vía.

Señalado lo anterior, toca indagar el fin o principios en los que está basada la prohibición del crowdfunding. En este sentido, creemos que el principio básico en el que se asientan todas estas medidas que suelen limitar o en su caso prohibir determinadas aportaciones privadas, se relacionan con la libertad que han de revelar los partidos políticos a la hora de tomar sus decisiones, lo que se traduce en una protección del ordenamiento jurídico hacia estas agrupaciones para que puedan ejercer sus funciones constitucionales de forma completa ${ }^{73}$. De hecho, cuando hacíamos mención a los posibles riesgos que podían llevar aparejadas las aportaciones crowdfunding, enunciábamos esencialmente dos; por una lado, los peligros específicos de esta fuente que se relacionaban con los problemas de identificación de los aportantes, y por otro lado, hacíamos referencia de forma general a los riesgos presentes en toda aportación privada, riesgos, que principalmente se ligaban a la posibilidad que podían tener determinadas personas de influir en las decisiones de los partidos políticos. De manera que la manifestación y formación de la voluntad popular quedaba limitada o restringida ${ }^{74}$, en la medida que unos pocos, aquellos que aportan más, pudieran influir en las decisiones de los partidos políticos. Es por ello que fines como la lucha contra la corrupción, o en su caso el libre ejercicio de actuación de los partidos políticos, estén detrás de la implantación de este tipo de medidas ${ }^{75}$, y más concretamente en el precepto que ahora analizamos. De manera que, en principio, estos fines de relevancia constitucional (corrupción

72 La doctrina suele utilizar indistintamente principio de proporcionalidad o test de proporcionalidad. Entre otros: ÁLVAREZ-OSSORIO MICHEO, F. (2014). «Tasas judiciales: entre principio de proporcionalidad y política de derechos fundamentales», Revista Española de Derecho Constitucional, n. ${ }^{\circ} 100$, enero-abril, págs. 221-242.

73 La exposición de motivos de la LOFPP justifica el recelo hacia las fuentes de financiación privadas en la medida que un control no férreo de estas, puede afectar a la formación correcta de la manifestación de la voluntad popular. (función constitucional de los partidos políticos)

${ }^{74}$ OLAIZOLA NOGALES, I. (2015). «Medidas de regeneración democrática. La nueva regulación de la financiación de los partidos políticos en España». Estudios de Deusto, Vol. 63/1, enero-junio, págs. 327-358, pág. 346.

75 La lucha contra la corrupción se propuso durante la tramitación de la LO del código penal como medida que justificara la penalización de determinadas conductas de financiación de partidos políticos y en la que en su caso estaría presente las aportaciones vía crowdfunding. Véase: Enmienda N. 586 presentada por UPYD, durante la tramitación de la reforma del código penal de 2015. BOCG de 10 de diciembre de 2014, pág. 395 y 396 o en la enmienda n. 727 presentada por el grupo PSOE. BOCG de 10 de diciembre de 2014, pág. 470 y ss. 
política y correcta formación de la manifestación y la voluntad popular) justifican una limitación de los derechos fundamentales y principios que están presentes en toda aportación crowdfunding.

Indicado por tanto los fines en los que se apoya la prohibición del crowdfunding, pasamos a analizar la proporcionalidad de dicha decisión.

Así, por lo que se refiere a la adecuación de la medida al $\mathrm{fin}^{76}$, esto es, que la medida sea idónea para conseguir el fin perseguido. En nuestro caso, creemos, que una norma que prohíbe las aportaciones vía crowdfunding, siendo extremadamente reacia a las aportaciones privadas, puede efectivamente conseguir los fines previamente señalados, ya que, al menos, se eliminaran los riesgos que llevan aparejados estas concretas contribuciones. De manera que, anulada la fuente que genera estos riesgos, se evita el problema y el fin se logra.

Por tanto, pasado este primer filtro, tocaría analizar el segundo sub principio de la proporcionalidad, es decir, la llamada necesidad de la medida ${ }^{77}$. Ello nos lleva a comprobar si dentro del abanico de posibilidades que tenía el legislador para llevar a la práctica el fin señalado, la prohibición de estas aportaciones era la medida menos gravosa. Debiendo por tanto valorar si esta norma es indispensable para conseguir el fin perseguido.

En tal sentido, creemos firmemente que existen otras medidas menos lesivas de los derechos fundamentales y principios estudiados y que están presentes en este tipo de aportaciones.

Ya señalábamos previamente, que preceptos que establezcan límites máximos de aportaciones o un plus de requisitos ligados a la certificación de la identificación del aportante pueden mitigar los riesgos que llevan aparejadas este tipo de contribuciones. En nuestro caso, el legislador, para conseguir el fin propuesto, ha optado por una de las medidas más severas y que más perjudican a los derechos y principios señalados, de ahí que consideremos que dicha medida no es proporcional.

Señalado por tanto esto último, ello bastaría para llegar a la conclusión de que esta opción legal es contraria a la Constitución, sin embargo, con el fin de consolidar nuestro argumento, creemos que es necesario analizar también la estricta proporcionalidad de la medida. En este orden de cosas, en este último test debemos de valorar si la medida objeto de control concede más beneficios o ventajas para el interés general, que perjuicios sobre otros bienes o valores en conflicto ${ }^{78}$. En nuestro caso, nos preguntamos si, a través de la prohibición de las aportaciones vía crowdfunding se generan más beneficios para el interés general (lucha contra la corrupción y protección correcta de la formación de la manifestación popular) que perjuicios sobre los derechos fundamentales atacados y los principios que están latentes en las aportaciones vía crowdfunding. En este orden de cosas, pensamos con toda firmeza que si bien, con la

${ }^{76}$ STC Núm. 66/1991 de 22 marzo. FJ 4

77 STC Núm. 136/1999 de 20 julio. FJ 28.

78 STC Núm. 140/2016 de 21 julio. FJ 10. 
prohibición de estas aportaciones se podría en su caso luchar contra la corrupción (adecuación de la medida), lo cierto es, que con esta medida no se lograría alcanzar el objetivo pleno de ese fin, ya que existen multitud de formas por las que se puede financiar de forma ilegal a un partido y en su caso influir en las decisiones de dichas agrupaciones políticas independientemente de que las aportaciones de crowdfunding estén o no prohibidas.

Junto a ello, y por lo que se refiere al grado de afectación de los derechos fundamentales y principios. Aunque es verdad que los particulares podrían manifestar esos derechos a través de otros métodos como son las donaciones normales, lo cierto es, que no encontramos una justificación tal a la prohibición de este recurso. Así, en primer lugar, las aportaciones crowdfunding reúnen las mismas características que están presentes en toda aportación privada permitida por la ley, es más, a través del crowdfunding se consigue fomentar el tipo de aportaciones deseadas por el legislador, poquito de muchos, de manera que, una legislación que prohíbe este tipo de aportaciones, discrimina unas y otras aportaciones privadas. En segundo lugar, y dado que en las aportaciones crowdfunding los derechos fundamentales aparecen más concretizados que en las donaciones normales en la medida que el aportante explicita el destino de su colaboración a un proyecto determinado, creemos que una norma que prohíbe dichas aportaciones puede afectar en mayor grado al contenido de estos derechos fundamentales.

Dicho lo anterior, consideramos que la prohibición sin más de estas aportaciones supone un sacrificio mayor de los derechos fundamentales y principios que están presentes en el crowdfunding, respecto del grado de realización del fin de la medida analizada, es decir, la lucha contra la corrupción y el mantenimiento de la libre formación de la voluntad. Señalado a la inversa, en este caso, el grado de realización del interés general presente en esta medida es mucho menor que el ataque a los derechos fundamentales y principios latentes en estas aportaciones. Ya que, por un lado, con la prohibición del crowdfunding no se lograría una plena erradicación de la corrupción, así como una plena libertad de estas asociaciones a la hora de tomar decisiones, y por otro lado, la restricción de los derechos fundamentales y principios mencionados sería total en la medida que en vez de optarse por disponer una regulación que pudiera legislar con la correspondiente cautela esta nueva fuente, y por tanto se establecieran limitaciones a los derechos fundamentales presentes en dicha recurso de forma justificada, en iguales o parecidas condiciones presentes en otras fuentes de financiación privadas como la donaciones normales, se opta por una legislación que como hemos dicho anula por completo la práctica de dicho recurso financiero.

En definitiva, la medida legal que analizamos no es contraria a la Constitución porque establezca límites a las aportaciones crowdfunding, las limitaciones a las aportaciones privadas responden en nuestra opinión a unos fines legítimos que se ven en su caso potenciados por un sistema constitucional que favorece la financiación pública ${ }^{79}$,

79 La jurisprudencia del Tribunal constitucional ha reconocido la financiación pública de los partidos políticos, en: STC Núm. 3/1981 de 2 febrero. FJ 2. 
el problema deviene en esta norma de la impracticabilidad total de dichas aportaciones. $\mathrm{Y}$ es que una normativa que no solo no permite este tipo de manifestaciones, sino que además, sanciona dichas conductas, consideramos que es contraria a la Constitución desde el momento que; por un lado se restringe sin justificación suficiente distintos derechos fundamentales como el derecho de asociación, libertad de expresión o libertad ideológica y por otro lado, porque además, se coarta una fuente de financiación que potencia algunas de las funciones constituciones que les vienen atribuidos a los partidos políticos.

\section{CONCLUSIONES}

1. El uso del crowdfunding por parte de los partidos políticos para su financiación se ha manifestado por dos cauces. Por un lado, a través de la financiación de la campaña electoral, y por otro, a la hora de financiar los gastos ordinarios de estas agrupaciones políticas.

2. Entre los beneficios que se le han atribuido al crowdfunding destaca el fomento de la participación de los ciudadanos en la estructura de los partidos políticos, traduciéndose generalmente dicha participación a través de aportaciones de pequeña cuantía.

3. Los principales riesgos que acarrea este nuevo mecanismo requieren de una respuesta por parte de nuestro legislador que, sin tender a la prohibición de esta nueva fuente de recursos para las agrupaciones políticas, si sea cautelosa y precavida con el fin de mitigar dichos riesgos. Fórmulas como la exigencia del certificado electrónico, así como otras señaladas en este trabajo irían por ese buen camino.

4. La regulación actual del crowdfunding en nuestras actuales normas de financiación resulta cuanto menos débil y defectuosa en razón a los términos expuestos. En este sentido, por lo que se refiere a la LOREG, se hace necesaria una reforma que prevea de forma clara esta nuevo recurso financiero, a su vez, en lo que respecta a la LOFPP, su actual redacción hace impracticable esta nueva herramienta, de ahí que sea necesario exceptuar el carácter finalista de estas aportaciones, carácter que como hemos señalado previamente viene entroncado en toda contribución que se realiza a través de este mecanismo, distinguiéndose por tanto de las donaciones normales cuyo destino va a parar a las arcas comunes de las agrupaciones políticas sin distinción alguna.

5. La prohibición de facto de esta nueva fuente de financiación privada de los partidos políticos es en nuestra opinión contraria a la Constitución, ya que vulnera los derechos fundamentales y principios que están latentes en este tipo de aportación de forma desproporcionada en los términos explicados en este trabajo. 
Title:

Crowdfunding and political parties financing

\title{
Summary:
}

I. An expected regulation. II. ¿What is crowdfunding? III Uses of crowdfunding in the financing of political parties. Crowdfunding in election campaigns. Crowdfunding in the ordinary financing of political parties. IV. The risk of crowdfunding in financial political parties. V. Legal Fit. VI. The constitutionality of crowdfunding. Rights present in crowdfunding contributions. Proportionality of the measure. Conclusions.

\section{Resumen:}

El crowdfunding se presenta como un nuevo recurso financiero privado para las arcas de los partidos políticos por el cual, los ciudadanos pueden participar económicamente en la estructura de dichas agrupaciones. En este artículo se expondrán algunas propuestas legales que traten de incorporar adecuadamente este nuevo recurso. Para ello, primeramente, realizaremos un acercamiento al análisis del crowdfunding con el objetivo de facilitar al lector el entendimiento de este fenómeno. En segundo lugar, se analizará la actual puesta en práctica de esta herramienta por parte de los partidos políticos a escala nacional e internacional, señalando algunos de los aspectos positivos y negativos que se pueden derivar del uso de este nuevo recurso. Todo ello, con el objetivo principal de analizar la viabilidad del crowdfunding en nuestro actual sistema de financiación de partidos políticos. Objetivo principal que nos llevará irremediablemente a proponer el encaje legal que consideramos adecuado de este instrumento en nuestro ordenamiento jurídico. Finalmente, se realizará un análisis constitucional de esta nueva fuente de financiación privada. Fuente que ya adelantamos, a día de hoy se encuentra prohibida de facto por el Art 4.2 h) de la Ley Orgánica de Financiación de Partidos Políticos, pudiendo comportar tal prohibición la inconstitucionalidad del mencionado precepto.

\begin{abstract}
:
Crowdfunding is presented as a new private financial resource for parties of political parties by which citizens can participate economically in the structure of these organizations. This paper will set out some legal proposals that seek to adequately incorporate this new resource. First, we will approach the crowdfunding analysis in order to make it easier for the reader to understand this phenomenon. Secondly, it will analyze the current implementation of this tool by political parties at national and international level, pointing out some of the positive and negative aspects that can be derived from the use of this new resource. All this, with the main objective of analyzing the viability of crowdfunding in our current
\end{abstract}


system of financing political parties. This is the main objective that will lead us irremediably to propose the legal reserve that we consider appropriate for this instrument in our legal system. Finally, a constitutional analysis of this new source of private financing will be carried out. Source that we have already advance, today it is prohibited by Article $4.2(\mathrm{~h})$ of the Law on Financing Political Parties, and this prohibition may entail the unconstitutionality of this precept

\section{Palabras claves:}

Crowdfunding; Partidos Políticos; Financiación política; Aportación Finalista.

\section{Key words:}

Crowdfunding; Political Parties; Political Financing; Finalist Contribution 